\title{
Saúde indígena e políticas públicas: alteridade e estado de exceşã *
}

Anita Guazzelli Bernardes ${ }^{1}$

BERNARDES, A.G. Indigenous health and public policies: alterity and state of exception. Interface - Comunic., Saude, Educ., v.15, n.36, p.153-64, jan./mar. 2011.

This article analyzes the forms of objectivation of indigenous peoples in Brazil regarding health public policies. This reflection has stemmed from the way in which indigenous peoples have become a focus of public policies since 1910, when the Service of Indigenous Protection and Localization of National Workers (SPI) was created. The discussion was grounded on the analysis of SPI's regulations from 1910 to 1963. The main line of investigation was the Foucauldian perspective of power/knowledge relations, as well as the concept of alterity and state of exception. The indigenous issue has been considered as an emergency in the territory of public policies and discussed as a historicalpolitical line which shapes both subjects and objects.

Keywords: Indigenous health. Signifying practices. Health public policies. Otherness. State of exception.
O artigo analisa as formas de objetivação das populações indígenas no Brasil no que tange às políticas públicas em saúde. A reflexão parte do modo como as populações indígenas se tornam foco de políticas públicas a partir do Serviço de Proteção ao Índio e Localização de Trabalhadores Nacionais (SPI), criado em 1910. A discussão ampara-se na análise das legislações do SPI no período entre 1910 a 1963. Utiliza-se, como linha principal de investigação, a perspectiva foucaultiana de relações de poder/saber, bem como o conceito de alteridade e estado de exceção. A questão indígena é considerada como emergência no território das políticas públicas e discutida como uma linha histórico-política que conforma sujeitos e objetos.

Palavras-chave: Saúde indígena. Práticas de significação. Políticas públicas de saúde. Alteridade. Estado de exceção.

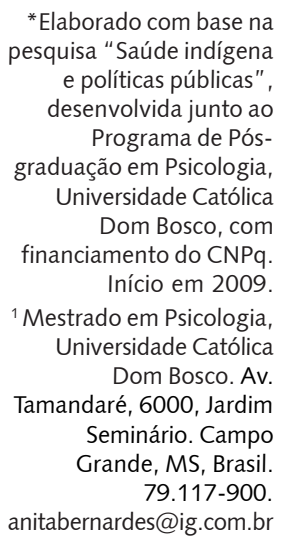


O propósito deste artigo é analisar as formas de objetivação das populações indígenas no Brasil no que tange às políticas públicas em saúde. A reflexão parte de considerações preliminares, de uma pesquisa intitulada Saúde Indígena e Políticas Públicas, a respeito do modo como as populações indígenas tornam-se foco de políticas públicas a partir do Serviço de Proteção ao Índio e Localização de Trabalhadores Nacionais - SPI, formulado em 1910.

A discussão ampara-se na análise das legislações do SPI entre o período de 1910 e 1963, tomando, como linha principal de investigação, a perspectiva foucaultiana de relações de poder/saber. Esse campo de análise considera os documentos do SPI como um conjunto de discursos efetivamente pronunciados, como acontecimentos, que apesar de se transformarem através da história, possibilitaram o aparecimento de outros discursos. Ou seja, a análise do SPI é considerada como a descrição de um arquivo, no sentido que Foucault (2000) dá ao conceito.

O exercício do pensamento circunscreve-se à análise de estratégias políticas voltadas para a saúde dos povos indígenas mediante o conceito de alteridade. Esta reflexão torna-se possível por meio da utilização das ferramentas conceituais de biopolítica, diferença e estado de exceção.

A emergência da questão indígena, no território das políticas públicas, é discutida como uma linha histórico-política. Operar com uma linha histórico-política engendra-se na forma como se levantam questões sobre uma determinada formação histórica. É um modo de interrogar-se sobre a saúde indígena e perscrutá-la como problemática teórico-política. Teórica e política na medida em que se formula em uma racionalidade e em uma mecânica do poder. São estratégias que apresentam a saúde indígena como um acontecimento, e não como uma evidência.

Em um primeiro momento, será discutido, neste texto, o conceito de cultura no que tange às práticas de significação e às biopolíticas. Mediante essas considerações, será apresentado o percurso das práticas em saúde voltadas para as populações indígenas. A partir disso, abre-se para uma análise dessas práticas em saúde, tomando, como fio condutor, a alteridade/diferença e o estado de exceção.

\section{Cultura: práticas de controle da vida}

Este texto parte da consideração da cultura como práticas de significação, que se organizam sob condições políticas, como jogos de forças em um determinado tempo-espaço. O que se quer apontar é que as práticas de significação que constituem o tecido social, a vida cotidiana, têm condições discursivas de existência. Não se trata de significações que nomeiam ações/objetos/sujeitos, mas de sentidos que constituem ações/objetos/sujeitos. As práticas de significação produzem materialidades, corpos e diferenças. Isso implica não separar aquilo que é visível do que é enunciável, porém ambos são irredutíveis um ao outro.

As práticas de significação, desse modo, não dizem o que algo é, sua essência, sua ontologia, e sim os acontecimentos que se tornam condições ontológicas. Por acontecimento compreende-se um conjunto de condições históricas, espaciais, existenciais, e não um grande evento disruptor de uma série de processos. O acontecimento é um conjunto de ações cotidianas de transporte, tradução e negociação de sentidos.

Apontar a cultura como campo de produção é entendê-la, também, do ponto de vista político, ético e estético. Isso porque, quando as práticas de significação são definidas mediante condições socioculturais, e essas condições compõem um campo de lutas, de forças, encontramos um plano de ações possíveis, isto é, um campo político (Foucault, 2003). Essas ações, engendradas sob condições discursivas de possibilidade, atuam sobre outras possibilidades de ações, o que implica diversidade de práticas, diversidade de sentidos. Esse plano político, que envolve a ética e a estética, põe em jogo essas duas dimensões e diz respeito às formas de governo, da ação da força sobre outra força e da força sobre si mesma. Segundo Deleuze (1992, p.125), "a ética é um conjunto de regras facultativas que avaliam o que fazemos, o que dizemos, em função do modo de existência que isso implica". Por estética, entende-se, de acordo com o mesmo autor, um plano de sensibilidade que indica um estilo de vida, um modo de existência.

Um plano político, nas palavras de Foucault (2004), significa um conjunto de relações de poder ou, melhor dizendo, de estratégias de poder que nos fazem ver, falar, viver de determinados modos, e não 
de outros. Essas estratégias de poder tanto são forjadas em um determinado local da cultura quanto são condições de possibilidade para uma cultura.

Colocar as práticas de significação em análise é operar com a cultura como um sistema aberto. Nesse plano de circunstâncias/acontecimentos, encontramos as estratégias de poder. Um poder que age sobre o viver, sobre as formas de vida a partir da modernidade. Um poder que, segundo Foucault (1999), não mais deixa viver e faz morrer, e sim, o contrário: faz viver e deixa morrer. Um biopoder que encontra, na vida, seu foco de investimento mediante estratégias biopolíticas. A vida passa a ser objeto das relações de força e de práticas de significação, a vida torna-se um fio condutor da cultura. Não a vida como fato, mas a vida como forma. Dessa maneira, olhar a cultura cria um plano ótico direcionado para as formas de viver e os modos como uma determinada cultura forja estratégias de controle da vida, estratégias de fazer viver ou deixar morrer.

O biopoder é possível quando, no século XIX, a relação entre indivíduo e sociedade começa a ser modificada. Em uma organização social na qual existe o corpo individual de um lado e a sociedade de outro, as estratégias de poder edificam-se de forma disciplinar. A partir do século XIX, como foi apontado, surge um novo problema: não se trata mais do indivíduo em seu meio natural, e sim dos efeitos da cidade, dos processos cada vez mais recrudescidos da urbanização. A urbanização repercute não mais em corpos individuais, mas sim nos indivíduos em seu conjunto - a população. No que tange às práticas de significação, passa a ocorrer outro tipo de jogo: não mais indivíduo-corpo-sociedade, e sim população-espécie-cidade. Isso não quer dizer que as práticas disciplinares e o foco nos indivíduoscorpos deixaram de existir. Emerge, isso sim, outro conjunto de práticas de significação, que traz consigo distintos modos de poder.

Ao tornar população-espécie-cidade como correlatos, ou seja, ao se considerar um, e instantaneamente o outro aparecer, cria-se uma urgência a ser respondida: as formas de viver da população em seu conjunto. A vida como forma de viver torna-se foco de investimentos do poder, isto é, a vida da população aparece como um problema político. Como problema político, não caberá mais apenas disciplinar os corpos individuais, e sim regulamentar a vida da população. Trata-se de uma economia política que cria a relação entre direito e vida: "direito de intervir para fazer viver, e na maneira de viver, e no como da vida" (Foucault, 2005, p.296). A biopolítica é uma estratégia de poder que, adotada pelo Estado moderno, produziu a intervenção/regulação no direito à vida, uma biorregulamentação pelo Estado.

É sob essas condições que se torna possível pensar a saúde, por exemplo, como estratégia biopolítica, como um conjunto de práticas de significação que organizam e regulamentam a população em seu conjunto. Assim, a saúde das populações torna-se foco do jogo político moderno. Esse jogo político é um conjunto heterogêneo que operacionaliza um saber sobre a vida (Medicina), um saber sobre o direito (Justiça) e um saber sobre a gestão da população (Economia Política). Esse jogo político capilariza-se no tecido social, estende-se do corpo-individual à população, utilizando, como estratégia, tanto a disciplina individual quanto a norma geral.

A biopolítica encontrará, nas políticas públicas, um modo de operacionalização. As políticas públicas como no caso da saúde - tornam-se um modo de regulação da população. Trata-se de uma estratégia de governo que objetiva uma universalidade nacional: o fortalecimento da cidade, mediante o investimento na população, e que tem como um dos princípios a identidade nacional. Nesse caso, a Nação passa a ser soberana sobre o indivíduo: é em razão da Nação que o poder sobre a vida passa a se organizar. A política pública, desse modo, é uma estratégia de investimento na Nação. Nesse plano, de conformação da Nação, entra em jogo o fazer viver e o deixar morrer. Ao mesmo tempo em que a biopolítica faz viver, ela mesma tem, como estratégia, o deixar morrer para fazer viver - cria-se um corte entre aquilo que estaria a serviço da Nação e aquilo que desestabilizaria a universalização da Nação.

Esses procedimentos políticos estabelecem uma cesura na população: a distinção entre grupos no interior da população; a qualificação de grupos como superiores e inferiores; a objetivação daquilo que deve viver e daquilo que pode morrer, ou seja, aquilo que qualifica culturalmente, de modo positivo e negativo, os grupos constitutivos de uma população. Agora, a população não é um conjunto de indivíduos, um contínuo biológico, e sim um conjunto subdividido de espécies, em subgrupos, que encontrará, como modo de organização da Nação, o que Foucault (2005) nomeia de racismo de Estado. 
As políticas públicas são mecanismos que marcam essas distinções, que fragmentam o contínuo biológico da população. Nesse caso, as políticas públicas são práticas de significação, pois trazem, em si mesmas, conjuntos de sentidos que justificam as próprias estratégias de poder, na medida em que a cesura da população será possível em razão das formas de objetivação dos diversos grupos constitutivos da Nação, das normas de regulação que a tornam possível. Isso não significa que a política pública não seja fundamental, entretanto, é importante marcar que aquilo que seria um mecanismo de equalização de direitos e suportes sociais acaba, justamente, por criar e recrudescer diferenças de acesso ao direito e aos suportes sociais - uma diferença marcada pelo racismo de Estado, e não pela alteridade.

\section{A emergência da questão indígena no território das políticas públicas}

Segundo dados da Funasa (2000), a população indígena, quando da chegada dos europeus ao Brasil no século XVI, era estimada em cinco milhões de pessoas. A "colonização" do Brasil é considerada como um diagrama de poder que tem, como fio condutor, o modelo de conquista do outro (Lima, 1995). A "colonização" iniciou um processo de dizimação dessa população tanto pelas práticas de "escravidão, trabalho forçado, maus tratos, confinamento e sedentarização em aldeamentos e internatos" (Lima, 1995, p.4), quanto pelas epidemias de doenças infecciosas causadas pelo contato do europeu com o indígena. A relação que o europeu estabeleceu com as populações indígenas baseou-se naquilo que Foucault (2005, p.307) aponta: "[...] o racismo vai se desenvolver primo com a colonização. Quando for preciso matar pessoas, matar populações, matar civilizações, como se poderá fazê-lo, se se funcionar no modo do biopoder? Através dos temas do evolucionismo, mediante um racismo".

Esse processo que se estabelece no encontro entre uma racionalidade "colonizadora" e as populações que encontra no território do qual se apropria engendra estratégias que se iniciam com práticas disciplinares e se ampliam para biopolíticas.

Entendida como uma rede que se estabelece entre um conjunto heterogêneo de organizações, discursos, regulamentações, proposições filosóficas, morais, científicas, que respondem a uma urgência histórica e constitui-se por jogos de força, a "colonização" é um dispositivo que, ao integrar, aniquila aquilo que difere (Foucault, 1995). As tecnologias desse dispositivo vão encontrar, no racismo, sua forma de justificativa, um racismo que se organizará desde práticas mais sutis de disciplina, como o confinamento e o sedentarismo, até práticas escravocratas e de trabalho forçado. Diante da questão social que se produz a partir dessas estratégias disciplinares, formulam-se políticas públicas voltadas para as populações indígenas, ou seja, formula-se um investimento biopolítico.

A partir de 1910, começa a engendrar-se uma política indigenista - SPI -, inserida no Ministério da Agricultura, justificada em uma ontologia indígena que considerava os índios "num estágio infantil da humanidade" (Funasa, 2000, p.4), mas passíveis de governo a partir de um processo de "evolução e integração na sociedade nacional por meio de projetos educacionais e agrícolas" (Funasa, 2000, p.4). Esse modo de conformação do indígena em uma categoria de desenvolvimento humano mais primitivo difere um pouco das primeiras formas de objetivação quando da chegada dos europeus. Nesses primeiros encontros, o campo de inteligibilidade voltado para a conquista do território geográfico, e não da população, colocava em dúvida, inclusive, a humanidade das populações indígenas. As práticas de significação alheias nos atos alheios dessas populações não apresentavam ainda formas de objetivação por parte do europeu, eram planos de ações que diferiam, que apresentavam um grau de alteridade que dificultava procedimentos de tradução e interpretação. Nesse caso, iniciar processos de categorização indígena, ou seja, uma ontologia indígena torna-se uma estratégia do próprio dispositivo de colonização. O recurso de inteligibilidade forjado tratava de agrupamentos humanos ou não. De acordo com Foucault (1992), foi preciso o desenvolvimento de um campo nomeado de ciências humanas, que tinha como eixos o trabalho, a linguagem e a vida, para que as populações indígenas começassem a ser objetivadas como categoria humana, quer dizer, como um "estágio infantil do desenvolvimento humano".

O SPI foi a primeira política pública voltada para as populações indígenas em que se criou a possibilidade de ação estatizada para essas populações, tendo como práticas de significação a correlação entre trabalho, vida e linguagem. Essas ações estatizadas, ou as formas de governo sobre os povos 
indígenas, tiveram como agenciamentos: primeiro, a definição de um estatuto jurídico, em que o conceito "índio" figuraria como status jurídico; segundo, as negociações entre a permanência ou não de militares na aplicação e no gerenciamento do SPI (Lima, 1995). Nesse sentido, o SPI tem uma dupla inscrição em termos de práticas de significação no campo das políticas públicas, na medida em que os povos indígenas passam a ter um estatuto jurídico como população do território nacional. Portanto, as populações indígenas passam a ser foco de investimentos políticos, bem como da articulação desse estatuto jurídico ao campo militar, ou seja, a nacionalização das populações indígenas é feita pelo exército. Na análise de Lima (1995, p.118): "a atribuição de indianidade seria a via de acesso e forma intermediária do cumprimento de um projeto de extinção dos povos nativos enquanto entidades discretas, dotadas de uma historicidade diferencial e de autodeterminação política" - seria uma forma de operacionalização de um racismo de Estado.

De acordo com Langdon (1999), até 1910, não havia políticas de saúde voltadas para as populações indígenas. Havia atendimentos esporádicos por parte de missionários. O SPI, criado em 1910, inicia um processo de intervenção, por parte do Estado, voltado para atender, entre outras problemáticas, a saúde indígena. Porém, as intervenções eram assistemáticas e desorganizadas. A desorganização e assistematização, quando analisadas como parte de um dispositivo, passam a ser compreendidas não como ausência de fundamentos médicos teórico-práticos, e sim como uma estratégia do próprio dispositivo. Trata-se de um projeto de integração com ações que objetivavam a proteção e enquadramento progressivo das populações indígenas no sistema produtivo nacional em razão de uma necessidade de pacificação das relações entre governo e povos indígenas, como descreve o Decreto $\mathrm{n}^{\circ}$ 8.072 (Brasil, 1910, p.1): "Art. 1․ a) prestar assistência aos índios do Brasil, que vivam aldeados, reunidos em tribos, em estado nômade ou promiscuamente com civilizados".

Essa assistência é descrita em relação a: direitos vigentes; posse da terra; respeito à organização interna das etnias; punição dos crimes contra as populações indígenas; fiscalização dos aldeamentos; vigilância para que as populações indígenas não sejam coagidas; manutenção de relações com essas populações por meio da figura do inspetor do serviço; inspetores como procuradores dessas populações; noções aplicáveis às suas formas de ocupação; melhoria de suas condições materiais de vida (habitação e meios de produção agrícola/industrial); restituição (sempre que possível) das terras que lhes foram tiradas; promoção da mudança de certos grupos indígenas; fornecimento de recursos musicais/artísticos; introdução da pecuária nos territórios indígenas; ensino de instruções primárias e profissionais aos filhos de indígenas; levantamento de dados sociodemográficos das populações indígenas. Esses indicadores de assistência e proteção não apresentavam a saúde em seu plano de ação. Os indicadores eram relativos à terra e ao trabalho, dois objetos que poderiam, articuladamente, atribuir o estatuto de "índios do Brasil".

As estratégias de proteção, enquadramento e pacificação surgem como tecnologias biopolíticas em razão do que foi apontado anteriormente como a emergência das populações indígenas como uma questão social. Não se trata de uma problemática constituída em razão da diversidade cultural com a qual as políticas públicas se defrontam, e sim de condições culturais em que a diferença é tornada uma questão social. Há emergência como questão social na medida em que as estratégias disciplinares utilizadas, até então, não são mais suficientes para o aniquilamento disso que diferia do projeto de desenvolvimento nacional - a visibilidade de uma população dentro do território nacional com uma "historicidade diferencial e de autodeterminação política" (Lima, 1995, p.118). A forma encontrada é justamente incorporar as populações indígenas ao sistema produtivo nacional. Entretanto, esse plano de ação defronta-se com uma problemática a ser equacionada: propriedade da terra e cidadania.

A operação de nacionalização em que se intenta equacionar propriedade da terra e cidadania é objeto não do campo da saúde, mas do Ministério da Agricultura, Indústria e Comércio. Nesse caso, não se tratava de um investimento biopolítico na saúde das populações indígenas. A saúde das populações indígenas entrava como um recurso de controle. O fazer viver ou deixar morrer organizavase com base na propriedade da terra, e não na cidadania - propriedade da terra da Nação, e não das populações indígenas, pois a figura existencial era "índios do Brasil". Isso aparece na política quando as populações indígenas passam a ser localizadas ao redor de postos. Esses postos eram unidades administrativas que regulavam as populações indígenas, eram os chamados aldeamentos. Essas populações indígenas, de diferentes etnias, eram localizadas ao redor dessas unidades administrativas, e 
que tinham, como administrador, a figura do exército - Inspetor do serviço. Essas populações haviam sido retiradas de seus territórios geográficos de origem e realocadas em um território passível de controle como trabalhador nacional: "o destino final da população indígena seria, pois, o mercado de trabalho rural, sob a rubrica de trabalhador nacional" (Lima, 1995, p.126), que justificava a introdução da pecuária, do ensino primário e profissional, a modificação das formas de habitação, cultivo agrícola e certas artes industriais. Isso evitava a migração para os centros urbanos, ao mesmo tempo em que oferecia, para os proprietários dos bens de produção, uma mão de obra de baixo custo. De acordo com a análise de Lima (1995, p.125):

Os índios selvagens eram os alvos principais da ação do Serviço não só por obstaculizarem o avanço sobre o interior ou se acharem em guerra, mas também por oferecerem melhores oportunidades para o trabalho de civilização: encontrando-se em estágio primitivo da inelutável marcha da humanidade para o progresso, indiscutivelmente inferiores, a educação adequada os impediria de se transformarem em indivíduos cheios de defeitos.

A política do SPI transformava as populações indígenas em uma categoria de trabalhador nacional, conformando-se como uma condição ontológica de humanidade. O investimento na saúde passa a ser um recurso para essa transformação. Em um dos relatórios (Museu do Índio, 2008) desses postos, aparece uma descrição sobre uma campanha de vacinação que apresenta um número inferior de vacinas para a população indígena em seu conjunto. A decisão do posto foi vacinar apenas os homens, e não as mulheres e crianças. Não se imunizando mulheres e crianças, a possibilidade de existência de determinadas etnias indígenas tornava-se precária. Vacinava-se apenas o homem, que era passível de tornar-se mão de obra rural. A assistência à saúde dessas populações era restrita a ações emergenciais e ao controle de nascimentos e óbitos. A distribuição de medicamentos e a assistência médica apenas aparecem no SPI quando este se refere aos Trabalhadores Nacionais (Brasil, 1911, p.8), que não eram classificados como população indígena, mas que deveriam: apresentar "capacidade de trabalho e absoluta moralidade" (Brasil, 1911, p.10), não ter cometido nenhum tipo de crime, se chefes de família ou homens solteiros, ser trabalhadores agrícolas e ter capacidade física para trabalhar. Tornar-se um trabalhador nacional seria prerrogativa para ter acesso à distribuição de medicações e assistência médica, o que, para as populações indígenas, seria possível de acordo com o "grau de civilização" que fosse apresentando, ou seja, com uma educação adequada e a progressiva pacificação.

Entretanto, a rubrica de trabalhador nacional não os tornava brasileiros, e sim "índios do Brasil". A criação dessa figura "índios do Brasil" será paulatinamente esquadrinhada em: " $1^{\circ}$ ) índios nômades; $2^{\circ}$ ) índios arranchados ou aldeados; $3^{\circ}$ ) índios pertencentes a povoações indígenas; $4^{\circ}$ ) índios pertencentes a centros agrícolas ou que vivem em promiscuidade com civilizados" (Brasil, 1928, p.15). Articuladas a essa taxionomia, estabelecem-se certas práticas que consideravam o processo de nacionalização como possibilidade de autonomia, ou seja, quanto maior o "grau de civilização" (Brasil, 1928, p.15), maiores as possibilidades de incorporação à Nação e, portanto, aos direitos atribuídos à população brasileira:

Art. 5. A capacidade, de fato, dos índios, sofrerá restrições prescritas nesta lei, enquanto não se incorporarem à sociedade civilizada. Art. $6^{\circ}$. Os índios de qualquer categoria, não inteiramente adaptados, ficam sob a tutela do Estado, que a exercerá segundo o grau de adaptação de cada um, por intermédio dos inspetores do Serviço de Proteção aos índios e localização de Trabalhadores Nacionais, sendo facultado aos ditos inspetores requerer em nome dos mesmos índios, perante as justiças e autoridades, praticando para o referido fim todos os atos permitidos em direito. (Brasil, 1928, p.15).

O SPI era um instrumento de controle e regulação das populações indígenas. Nesse caso, o fazer viver ou deixar morrer entrava como parte desse processo. Quanto mais "civilizados", maiores as possibilidades de fazer viver. Quanto mais distantes do que se estabelecia por "civilizados", maior a possibilidade de deixar morrer. O fazer viver ou deixar morrer organizava-se como biopolítica mediante a lógica da tutela do Estado. 
Em 1934, o SPI migra da superintendência da agricultura e trabalho para o Ministério da Guerra. Esse processo tem como racionalidade uma lógica que se estrutura na relação entre populações indígenas e fronteiras:

Que o índio é aí um elemento precioso pelas suas qualidades morais, robustez física e adaptabilidade aos climas, que convém aproveitar e educar pelos métodos próprios, chamando-o à nossa nacionalidade antes que os países limítrofes os chamem à sua; Que em se tratando de problemas de fronteiras e de resguardo da nacionalidade, o Ministério da Guerra é naturalmente o indicado para superintendê-los. (Brasil, 1934, p.20).

Desse modo, a questão indígena assume uma nova conformação. Não se trata de uma regulamentação e controle com base na propriedade da terra e da força de trabalho, e sim com base nas fronteiras da Nação brasileira com outras Nações, um "elemento precioso" nesse processo. A questão indígena aparecerá como parte estratégica do Ministério da Guerra, da proteção das fronteiras e povoação de espaços limítrofes. O que se quer apontar com isso é a visibilidade que assume a questão indígena, em que a nacionalização não se constitui em razão dessas populações habitarem o território nacional, e sim devido a uma estratégia para salvaguardar o território nacional. Isso implicará que as políticas voltadas para essas populações não incluirão a saúde como um eixo das ações. O processo de nacionalização e incorporação das populações indígenas terá como tecnologias de governos: "medidas e ensino de natureza higiênica; escolas primárias e profissionais; exercícios físicos em geral e especialmente militares; educação moral e cívica; ensino de aplicação agrícola e pecuária" (Brasil, 1936, p.23). Essas são estratégias de cunho pedagógico e militar, e a saúde entrará como uma derivada da modificação dos hábitos indígenas, uma pedagogia dos comportamentos para torná-los mais higiênicos e militarizados. Essa pedagogia dos comportamentos acaba por engendrar um campo de significações em práticas de saúde que a consideram como de responsabilidade individual: cabia ao índio civilizar-se. A saúde das populações indígenas não é uma questão de direito e cidadania, não sendo, então, um dever do Estado, e sim um dever dessas populações para se nacionalizarem e integrarem - por isso, o ensino higiênico, a escolarização, a militarização e a educação moral e cívica. Trata-se do cívico não em termos de direitos indígenas, mas de deveres indígenas. Na medida em que essas práticas não objetivavam as populações indígenas como cidadãs, a equação tratava de civilizar, e não atribuir cidadania.

É apenas em 1942, com o Decreto-Lei № 10625, que a vida indígena se torna objeto de políticas públicas. Essa modificação ocorre quando o SPI migra novamente para o Ministério da Agricultura, engendrando a objetivação das populações indígenas mediante proteção, assistência e amparo à vida. Assim, a vida indígena entra no rol das atribuições da Nação brasileira, mas como vida articulada à terra, e não diretamente à saúde. A articulação com a terra torna-se uma tecnologia do dispositivo de colonização, que terá como finalidade "evitar o extermínio das tribos, quer decorra de hostilidades recíprocas, quer provenha de luta com os civilizados, competindo-lhe, ainda, educar e instruir o índio, incutindo-Ihe a ideia de que faz parte da nação brasileira" (Brasil, 1942, p.39).

Esse investimento na vida indígena terá, como lógica, "medidas tutelares traçadas pelo Estado" (Brasil, 1942, p.39). A vida indígena fica sob a tutela do Estado, o que se justifica em uma racionalidade que objetiva as populações indígenas com "graus de civilização" menores em relação aos "civilizados". O jogo que se estabelece estrutura-se em uma taxionomia, em práticas de significação que, por um lado, objetivavam, como brasileiros, os indivíduos das populações "civilizadas" e, por outro, esquadrinhavam as populações indígenas como parte da nação brasileira em processo de civilização. As populações indígenas não são populações brasileiras, são "parte da nação brasileira", com um estatuto jurídico que as diferencia e que se articula à necessidade de tutela.

A partir da década de 1950, o Ministério da Saúde inicia um plano de ações voltadas para as populações indígenas e rurais de difícil acesso. O plano se caracterizava por envolver campanhas de "vacinação, atendimento odontológico, controle de tuberculose e outras doenças transmissíveis" (Funasa, 2000, p.4). A formulação de um Ministério da Saúde abre espaço para que, em 1963, mesmo estando o SPI sob a gerência do Ministério da Agricultura, se incorpore, em suas ações, a execução de "planos de assistência médico-sanitária para os índios" (Brasil, 1963, p.46). Esse plano de ações 
encontra-se com a problemática das condições ontológicas que objetivavam as populações indígenas, bem como com uma política de racismo de Estado que investia mais no deixar morrer do que no fazer viver (Funasa, 2000, p.5): "As iniciativas de atenção à saúde indígena geralmente ignoram que os povos indígenas possuem seus próprios sistemas de representações, valores e práticas relativas ao adoecer e buscar tratamento, bem como seus próprios especialistas".

É nesse sentido que operar com a cultura auxilia a pensar sobre os processos de "civilização" voltados para a questão indígena. A cultura, ao ignorar "sistemas de representação, valores e práticas" das populações indígenas, o faz de acordo com o próprio mecanismo que a constitui: diferenciar, discriminar, produzir campos de força que se organizam em sistemas de referência, aplicabilidade e capacidade. Mais do que ignorar, captura-se aquilo que se diferencia das formas de objetivação dos não-indígenas. É uma mecânica que torna o outro igual não em termos de direitos, e sim de práticas de significação.

Entretanto, como campo de lutas, a questão indígena insiste e persiste, sendo que as modificações que as políticas sofrem são decorrentes dessa insistência. Insistência em tornar-se diferente daquilo que a cultura produz como igual. O movimento indígena incorpora o direito como sistema de referência e, conjuntamente com outros movimentos sociais, passa a figurar no campo de discussões de políticas públicas próprias voltadas para suas organizações sociais. É em decorrência desses jogos de forças que a saúde indígena emerge como política pública própria, e não mais como eixo de outras estratégias políticas, a partir de 1986, com I Conferência Nacional de Proteção à Saúde do Índio, por indicação da VIII Conferência Nacional de Saúde (Funasa, 2000).

\section{Saúde indígena, estado de exceção e diferença}

O exercício de problematizar a saúde indígena mediante uma linha histórico-política permite, a partir do conceito de biopolítica, considerar as relações que se estabelecem entre uma lógica de territórios geográficos objetivados como Nação e territórios de existências forjados dentro dessa Nação. A análise parte do que foi desenvolvido, anteriormente, sobre a emergência da saúde indígena como estratégia biopolítica, considerando, agora, os jogos que se estabelecem entre tutela e estado de exceção, entre nacionalização e diferença. Não se trata de considerar esses eixos em uma racionalidade binária, mas de pensar os planos de articulação que criam formas de bifurcação. Formas de bifurcação que se organizam a partir da consideração das condições de saúde das populações indígenas, que apresentam taxas de morbidade e mortalidade superiores às das populações não-indígenas (Funasa, 2000). Trata-se de um plano político que diz respeito às relações entre governo, ética e estética.

O plano político é o modo de considerar - como foi escrito nas seções anteriores - a maneira como a vida das populações indígenas inscreve-se na ordem estatal: "[...] é como se toda valorização e toda politização da vida implicasse necessariamente uma nova decisão sobre o limiar além do qual a vida cessa de ser politicamente relevante, é então somente vida sacra e, como tal, pode ser impunemente eliminada" (Agambem, 2007, p.146).

Esse limiar em que a vida cessa de ser politicamente relevante passa a ser considerado mediante mecanismos de exceção. O que se quer apontar é que, ao se tomar a vida das populações indígenas como eixo de investimentos políticos, criou-se a necessidade de se qualificar essas vidas. O modo de qualificar baseia-se nas formas de viver que essas vidas assumem e no estatuto jurídico que as inscreve na ordem estatal. As coordenadas para qualificar a vida das populações indígenas como politicamente relevantes sofrem algumas descontinuidades históricas, entretanto, essas descontinuidades colocam permanentemente em jogo a relação entre o mesmo e o outro, entre o idêntico e a diferença, de modo a enlaçar aspectos éticos e estéticos, abrindo, assim, um campo para a reflexão sobre a alteridade.

As descontinuidades lançam o olhar para o conceito de alteridade, cujos fundamentos se encontram nessas relações entre o mesmo e o outro. As populações indígenas, desde os primeiros encontros com os europeus, foram objetivadas como estranhas e estrangeiras (mesmo sendo, na realidade, os europeus os estrangeiros no território que "colonizavam"). Essas conformações existenciais tomadas como estranhas/estrangeiras não eram, entretanto, fruto de uma relação com o outro, e sim com o mesmo, na medida em que a racionalidade que organizava as ações europeias se baseava na lógica da conquista 
do outro, outro que deve tornar-se o mesmo, uma ontologia do mesmo. Essa condição de tornar o outro em um mesmo forja um estatuto de exceção para as populações indígenas, tanto em relação à sua tutela quanto em relação aos modos de dizimá-las.

O estatuto de exceção baseia-se nas discussões de Agambem (2004) sobre estado de exceção. Nesta reflexão, em que o estado de exceção é tomado como paradigma de governo, consideram-se as condições mediante as quais os direitos civis, assim como as liberdades individuais, estão suspensos. A justificativa para essa suspensão encontra-se na lógica de salvaguardar a segurança e a ordem pública, a defesa da Nação, um "estado de necessidade interna" (Agambem, 2004, p.30) inerente à existência do Estado. Os exemplos, entre outros, dessa forma de organização política encontram-se nos campos de concentração alemães, nos gulags russos, na ditadura militar no Brasil. São conformações em que o direito à vida perde o seu caráter de relevância e o Estado/Nação o assume. Nesse jogo, algumas vidas passam a ser consideradas "indignas de serem vividas" (Agambem, 2004, p.146), articulando-se a um novo estatuto jurídico de "vida sem valor". Entretanto, os exemplos acima circunscrevem espaçostempo delimitados, temporários, suspensões momentâneas levadas ao extremo, mas que encontram um ponto de ruptura quando as organizações políticas que lhes davam forma se transformavam em outras formas. A questão indígena, por outro lado, não apresentou um estatuto de exceção em um determinado tempo-espaço: ela conforma-se, justamente, com base em uma lógica da exceção, da suspensão. O estado de direito dessas populações, desde os primeiros contatos com os europeus, circunscreveu-se em um território de vidas dignas ou não de serem vividas.

A dignidade da vida das populações indígenas era condicionada ao "grau de civilização" que essas populações assumissem, e a tutela tornou-se o mecanismo mediante o qual se criaram as condições para esse processo "civilizatório". Nesse sentido, mesmo com "graus de civilização" maiores, os direitos indígenas encontravam-se condicionados à tutela. A tutela tornou-se um instrumento biopolítico de inscrever o direito à vida das populações indígenas em um estatuto de exceção: "índios do Brasil". A responsabilidade/tutela do Estado pelas populações indígenas engendra-se em um "estado de necessidade interna", de salvaguardar o desenvolvimento da Nação. É necessário tornar as populações indígenas "índios do Brasil", porém sob um diagrama que coloca essas vidas frente a um limiar de politicamente relevantes ou não. O fazer viver ou o deixar morrer irá organizar-se sob a articulação entre "civilização", Nação, necessidades.

Essa articulação não assegura o direito à vida das populações indígenas, ela apenas serve como ferramenta para investir ou não nas formas de viver. Mesmo em se tratando de incentivos à vida, isso não salvaguardará as populações indígenas do deixar morrer, na medida em que as formas de vida "civilizatórias" também apresentavam mecanismos de aniquilação da vida, como é observado nos aldeamentos, que colocavam as populações indígenas em uma condição de confinamento. É justamente esse jogo que anuncia o estado de exceção.

O estado de exceção encontrará não apenas na biopolítica as suas condições de emergência, mas, também, no que foi assinalado antes, na conformação de territórios existenciais. A conformação de territórios existenciais tem como condições ontológicas as relações entre o mesmo e o outro, entre um si e o outro. No primeiro jogo, o "colonizador" assume a figura daquele que hospeda o estrangeiro, ou seja, ao considerar o indígena um estranho, o "colonizador" cria um estatuto jurídico para torná-lo nomeável, apreensível, passível de regulação: é o estranho que deve tornar-se um igual, que deve falar a língua que não é sua, adquirir hábitos que não os seus (Derrida, 2003). O "colonizador", na condição de tutor, estabelece as coordenadas ontológicas da existência: ser civilizado, ser "índio do Brasil", ser trabalhador nacional. Um processo de constituição do outro que acaba, justamente, com a qualidade de ser outro, com a radicalidade da alteridade.

O estado de exceção permite essa empresa, aliás, é constitutivo da suspensão do outro e transformação em um mesmo. A saúde entraria como um mecanismo de tornar o outro um mesmo, na medida em que esquadrinha, seleciona, categoriza, aniquila potências de diferenciação do outro, da alteridade. Aldear as populações indígenas, tutelá-las, estabelecer graus de civilização e tecnologias de regulamentação do processo civilizatório indígena são processos de produção de existências com base na lógica do mesmo. O confinamento e a exceção enjaulam a diferença, aprisionam a alteridade. A estética é a do mesmo, aquilo que provoca, aquilo que causa estranhamento ou é tomado como exótico 
ou mecanicamente tornado igual. Em ambas as situações, a alteridade é colocada em suspensão: seja na parede, quando considerada artesanato, seja nos graus de civilização, quando se consideram os "índios do Brasil". Ao tornar-se uma questão social, uma evidência para as políticas públicas, a saúde indígena passa a figurar como estratégia de captura do outro/alteridade e transformação no mesmo. A condição ontológica da diferença, do outro, que seria a condição mesma da alteridade, é suspensa e transformada em um mesmo, um mesmo diferente, porém esquadrinhado em "graus de civilização" : índios nômades; índios arranchados ou aldeados; índios pertencentes a povoações indígenas; índios pertencentes a centros agrícolas ou que vivem em promiscuidade com civilizados (Brasil, 1928).

A relação entre um si e o Outro, cujas coordenadas são constituídas pela alteridade, encontra-se justamente nas práticas de liberdade, na insistência das populações indígenas em não se tornarem o mesmo. Não se trata de um processo de libertação, pois as políticas públicas foram paulatinamente incluindo as populações indígenas cada vez mais, mesmo que fosse para deixá-las morrer - são práticas de negociação com as políticas públicas, práticas que modificam as próprias políticas. E essa negociação engendra-se em uma estética do outro.

O estado de exceção cria condições para práticas de resistência, mesmo que ambos sejam formas que escapem ao âmbito jurídico, pois são ações que extrapolam a esfera do direito. O que está em articulação aqui é a possibilidade de liberdade, de práticas de liberdade. Onde há um espaço de suspensão de direitos, cria-se um espaço de não-escravidão. As práticas de não-escravidão, entendidas como práticas de liberdade, engendram territórios existenciais a partir da alteridade, entendendo-se que as práticas de liberdade são condições constitutivas da ética (Foucault, 2004). Ao cuidarem de si mesmas como um movimento social, as populações indígenas criam rasgos no estado de exceção, criam novos territórios existenciais, não sendo mais o que eram antes dos primeiros contatos com os europeus, não sendo mais o que passam a ser quando se tornam "índios do Brasil". Elas se tornam não uma questão social, mas uma questão de alteridade. A biopolítica encontra-se aqui com a biopotência. A política sobre a vida depara-se com a potência da vida, o que edifica novas práticas de significação, novas estéticas da existência.

\section{Referências}

AGAMBEN, G. Homo sacer: o poder soberano e a vida nua. Belo Horizonte: Editora UFMG, 2007.

Estado de exceção. São Paulo: Boitempo, 2004.

BRASIL. Ministério da Justiça. Decreto $n^{\circ}$ 8.072, 20 de junho de 1910. Dispõe sobre a criação do Serviço de Proteção ao Índio e Localização de Trabalhadores Nacionais. In: LIMA, A.C.S. Um grande cerco de paz: poder tutelar e indianidade no Brasil. 1992. Tese (Doutorado) - Universidade Federal do Rio de Janeiro, Rio de Janeiro. 1992. v. II, anexo $\mathrm{n}^{\circ} 1$, p. $1-8$.

Ministério da Justiça. Decreto $n^{\circ}$ 9214, 15 de dezembro de 1911. Dispõe sobre a Regulamentação do Serviço de Proteção ao Índio e Trabalhadores Nacionais. In: LIMA, A.C.S. Um grande cerco de paz: poder tutelar e indianidade no Brasil. 1992. Tese (Doutorado) - Universidade Federal do Rio de Janeiro, Rio de Janeiro. 1992. v. II, anexo $\mathrm{n}^{\circ} 1$, p. 8-15.

Ministério da Justiça. Decreto $n^{\circ} 5484,27$ de junho de 1928. Dispõe sobre a regulamentação da situação dos índios nascidos no território nacional. In: LIMA, A.C.S. Um grande cerco de paz: poder tutelar e indianidade no Brasil. 1992. Tese (Doutorado) - Universidade Federal do Rio de Janeiro, Rio de Janeiro. 1992. Anexo no 2 , p. 15-19. 
Ministério da Justiça. Decreto $n^{\circ} 24700,12$ de julho de 1934. Dispõe sobre a transferância do SPI ao Ministério da Guerra. In: LIMA, A.C.S. Um grande cerco de paz: poder tutelar e indianidade no Brasil. 1992. Tese (Doutorado) - Universidade Federal do Rio de Janeiro, Rio de Janeiro. 1992. Anexo n 2,p. 20-21, 1992.

Ministério da Justiça. Decreto $n^{\circ}$ 911, 6 de abril de 1936. Dispõe sobre a suspensão da execução do Regulamento da Inspetoria Especial de Fronteiras e Estabelece a subordinação ao Serviço de Proteção ao Índio. In: LIMA, A.C.S. Um grande cerco de paz: poder tutelar e indianidade no Brasil. 1992. Tese (Doutorado) Universidade Federal do Rio de Janeiro, Rio de Janeiro. 1992. v. II, anexo no 1, p. 21.

Ministério da Justiça. Decreto-Lei $\mathrm{n}^{\circ} 10625,16$ de outubro 1942. Dispõe sobre a aprovação do Regimento da Serviço de Proteção aos Índios. In: LIMA, A.C.S. Um grande cerco de paz: poder tutelar e indianidade no Brasil. 1992. Tese (Doutorado) Universidade Federal do Rio de Janeiro, Rio de Janeiro. 1992. v. II, anexo no 1, p. 34-39.

Ministério da Justiça. Decreto $n^{\circ} 52668,11$ de outubro de 1963. Dispõe sobre a aprovação do Regimento do Serviço de Proteção aos Índios do Ministério da Agricultura. In: LIMA, A.C.S. Um grande cerco de paz: poder tutelar e indianidade no Brasil. 1992. Tese (Doutorado) - Universidade Federal do Rio de Janeiro, Rio de Janeiro. 1992. v. II, anexo no 1, p. 46-49.

DELEUZE, G. Conversações. Rio de Janeiro: Ed. 34, 1992.

DERRIDA, J. Anne Dufourmantelle convida Jacques Derrida a falar da hospitalidade. São Paulo: Escuta, 2003.

FOUCAULT, M. Em defesa da sociedade. São Paulo: Martins Fontes, 2005.

A ética do cuidado de si como prática de liberdade. In: escritos V. Rio de Janeiro: Forense Universitária, 2004. p.264-87.

Ditos e Poder e saber. In Universitária, 2003. p.223-40.

Ditos e escritos IV. Rio de Janeiro: Forense

A arqueologia do saber. Rio de Janeiro: Forense Universitária, 2000.

História da sexualidade I: a vontade de saber. Rio de Janeiro: Graal, 1999.

Microfísica do poder. Rio de Janeiro: Edições Graal, 1995.

As palavras e as coisas. São Paulo: Martins Fontes, 1992.

FUNASA. Política Nacional de Atenção à Saúde dos Povos Indígenas. Brasília: Funasa, 2000.

LANGDON, J.E. Saúde e povos indígenas: os desafios na virada do século. Disponível em: <http://www.cfh.ufsc.br/nessi/Margsav.htm>. Acesso em: 19 mar. 2008.

LIMA, A.C.S. Um grande cerco de paz: poder tutelar, indianidade e formação do Estado no Brasil. Petrópolis: Vozes, 1995.

MUSEU DO ÍNDIO. Microfilme n 001: IR5 Benjamin Constant Posto n 81,13 Plans. Campo Grande: Cópia no centro de Documentação Teko Arandu/NEPPI/UCDB, 2008. Microfilme. 
BERNARDES, A.G. Salud indígena y políticas públicas: la alteridad y el estado de excepción. Interface - Comunic., Saude, Educ., v.15, n.36, p.153-64, jan./mar. 2011.

El artículo analiza las formas de objetivación de las poblaciones indígenas en Brasil en lo que respecta a las políticas públicas de salud. La reflexión parte de cómo los pueblos indígenas se convirtieron en el foco de las políticas públicas a partir del Servicio de Protección de los Índios y de la Ubicación Nacional de Trabajadores (SPI), formulados en 1910. El debate busca refugio en el análisis de las legislaciones de los SPI entre los años 1910 a 1963. Se utiliza como la principal línea de investigación la perspectiva foucaultiana de las relaciones de poder / saber, y el concepto de alteridad y el estado de excepción. La cuestión indígena es considerada una emergencia en el territorio de las políticas públicas y es debatida en una línea histórica y política que relaciona los sujetos y objetos.

Palabras clave: Salud de los indígenas. Prácticas de significación. Politicas públicas de salud. Alteridad. Estado de excepción.

Recebido em 09/11/09. Aprovado em 04/11/10 